\title{
Distal oblique metatarsal osteotomy technique in hallux valgus deformity: Clinical and radiological results
}

\author{
Ahmet Yiğit Kaptan, MD(D, Ali Turgay Çavuşoğlu, MD²(1), Mehmet Ali Tokgöz, MD²(D, \\ Tarık Elma, MD²iD, Aliekber Yapar, MD² \\ ${ }^{1}$ Department of Orthopedics and Traumatology, University of Health Sciences, Dr. Sami Ulus Maternity, Children's Health and \\ Diseases Training and Research Hospital, Ankara, Turkey \\ ²Department of Orthopedics and Traumatology, Gazi University Faculty of Medicine, Ankara, Turkey
}

Hallux valgus is the most common foot deformity in adults, particularly in the female population. ${ }^{[1]}$ Inheritance plays a significant role in the etiology of hallux valgus. ${ }^{[2]}$ Patients' history reveal that this deformity is also observed in other family members. However, the increase of hallux valgus deformity due to footwear should not be ignored. Particularly restrictive shoes produced from hard material lead to hypertrophy and inflammation of bursa on medial protrusion at the distal end of first metatarsal as a consequence of repeated load transfer from the medial of first metatarsal to the shoe. ${ }^{[2-5]}$ Menz et al. ${ }^{[6]}$ reported a significant relationship between the development of hallux valgus and the wearing of restrictive shoes.

For the patients, the cause of seeking medical help is pain rather than esthetic concerns and although improving the esthetic appearance of the foot is important, the most significant indication for surgical treatment is pain. ${ }^{[7]}$ The pain can sometimes make it difficult for a patient to wear shoes, and these

Received: September 04, 2019

Accepted: October 08, 2019

Published online: March 02, 2020

Correspondence: Ahmet Yiğit Kaptan, MD. Dr. Sami Ulus Kadın

Doğum, Çocuk Sağlığı ve Hastalıkları Eğitim ve Araștırma

Hastanesi Ortopedi ve Travmatoloji Kliniği, 06080 Altındağ,

Ankara, Türkiye.

E-mail: dryigitkaptan@gmail.com

Doi: 10.5606/ehc. 2020.71298

Citation: Kaptan AY, Cavuşoğlu AT, Tokgöz MA, Elma T, Yapar A. Distal oblique metatarsal osteotomy technique in hallux valgus deformity: Clinical and radiological results. It Dis Relat Surg 2020;31(1):88-94

\section{ABSTRACT}

Objectives: This study aims to evaluate the radiological and functional outcomes of hallux valgus patients treated with distal oblique metatarsal osteotomy technique.

Patients and methods: Twenty-six feet of 22 patients ( 4 males, 18 females; mean age $46.2 \pm 18$ years; range, 16 to 70 years) who were diagnosed as hallux valgus between March 2013 and April 2016 and who underwent distal oblique metatarsal osteotomy were included in this retrospective study. American Orthopedic Foot and Ankle Society/Hallux Metatarsophalangeal-Interphalangeal Scale (AOFAS/HMIS) was used for clinical and functional evaluation. The hallux valgus angle (HVA), intermetatarsal angle (IMA), distal metatarsal articular angle (DMAA), sesamoid position, first metatarsal length and forefoot bone and soft tissue width were measured for radiological evaluation.

Results: The mean follow-up time was $33.1 \pm 9.8$ months. The AOFAS/HMIS score increased significantly postoperatively $(p=0.001)$. In the footwear section of the AOFAS/HMIS, the median preoperative score of 5 (range, 0-5) increased to 10 (range, 5-10) at the postoperative period $(\mathrm{p}=0.001)$. Hallux valgus angle, IMA, DMAA, and first metatarsal length significantly decreased when compared to preoperative measurements. Forefoot bone width also decreased significantly from $9.3 \mathrm{~cm}$ (range, $7.5-11.5 \mathrm{~cm})$ to $8.8 \mathrm{~cm}(6.8-10.3 \mathrm{~cm})(\mathrm{p}=0.001)$.

Conclusion: Distal oblique metatarsal osteotomy is a safe method for hallux valgus deformity. Forefoot width reduction, decrease of soft tissue tension, sesamoid reduction, and plantar fascia relaxation are the crucial benefits of this method.

Keywords: Forefoot width, hallux valgus, metatarsalgia, oblique osteotomy.

patients have problems even in business, social life, and sports activities. Being able to choose footwear freely is an important indicator that determines the success of surgery both for the patient and surgeon. Our hypothesis was that distal oblique metatarsal osteotomy is a safe method that improves patient comfort and satisfaction in the postoperative 
period. ${ }^{[8]}$ Therefore, in this study, we aimed to evaluate the radiological and functional outcomes of hallux valgus patients treated with distal oblique metatarsal osteotomy technique.

\section{PATIENTS AND METHODS}

This study was conducted at Gazi University Faculty of Medicine and it included 26 feet of 22 patients (4 males, 18 females; mean age $46.2 \pm 18$ years; range, 16 to 70 years) who were diagnosed as hallux valgus between March 2013 and April 2016 and who underwent distal oblique metatarsal osteotomy. The data were collected prospectively for every patient preoperatively but evaluated retrospectively. The patients with previous hallux valgus surgery for the affected foot, inflammatory disease, peripheral vascular disease, or peripheral neuropathy were excluded. Surgical treatment was recommended for patients who were diagnosed with hallux valgus and who had difficulty in footwear, sport activities, and working after conservative treatment methods. There was also no evidence of metatarsophalangeal (MTP) joint degeneration for the included patients. All patients were evaluated pre- and postoperatively clinically and radiologically. Minimum duration of follow-up was 24 months. American Orthopedic Foot and Ankle Society/Hallux MetatarsophalangealInterphalangeal Scale (AOFAS/HMIS) was used for clinical evaluation. This scale consists of three parts as pain (40 points), function (45 points), and alignment (5 points). Activity limitations, footwear requirements, and MTP joint motion, which are components of the function part, were evaluated separately. Visual analog scale (VAS) was also used to assess pain and satisfaction. The study protocol was approved by the Gazi University Faculty of Medicine Ethics Committee. A written informed consent was obtained from each patient. The study was conducted in accordance with the principles of the Declaration of Helsinki.

Weight-bearing anteroposterior (AP) and lateral radiographs were obtained pre- and postoperatively for radiological evaluation. The hallux valgus angle (HVA), intermetatarsal angle (IMA), distal metatarsal articular angle (DMAA), sesamoid position, first metatarsal length, and forefoot bone and soft tissue width were measured preoperatively and after last follow-up. The method described by Zettl et al. ${ }^{[9]}$ was used for sesamoid position evaluation. First metatarsal length was distance from the distal end of the metatarsal head to the bisection of metatarsal base. For the measurement of forefoot bone width at weight-bearing AP radiograph, the distance remaining between the distal outer margins of the first metatarsal and the fifth metatarsal was measured. The distance between soft tissue shadows was measured using the same method for the forefoot soft tissue width (Figure 1).

The patients were placed in the supine position on the operating table. Under an ankle after pneumatic tourniquet was applied, dorsomedial approach was used over the one third of distal metatarsal. The skin and subcutaneous tissue were incised by straight incision and joint capsule was opened in the form of U-shape (Figure 2a). After the bunion excision, the metatarsal shaft was osteotomized from metatarsal shaft-neck conjunction area at an angle of $30-45^{\circ}$ in a distal medial to proximal lateral direction with respect to the first metatarsal length, deformity, and plantar fascia tension (Figure 2b). Sliding on the surface of the osteotomy was achieved not by active manipulation, but by bringing the thumb to the ideal position (Figure 2c). The sliding of the osteotomy site with this method occurred in different amounts according to the soft tissue tension that was different in each patient. Then, the first phalanx remained unsupported in the desired position and no soft tissue tension (particularly plantar fascia) was observed in this position to cause the deformity again. In addition, no additional soft tissue (adductor muscle, lateral capsule, plantar fascia, etc.) release was performed.

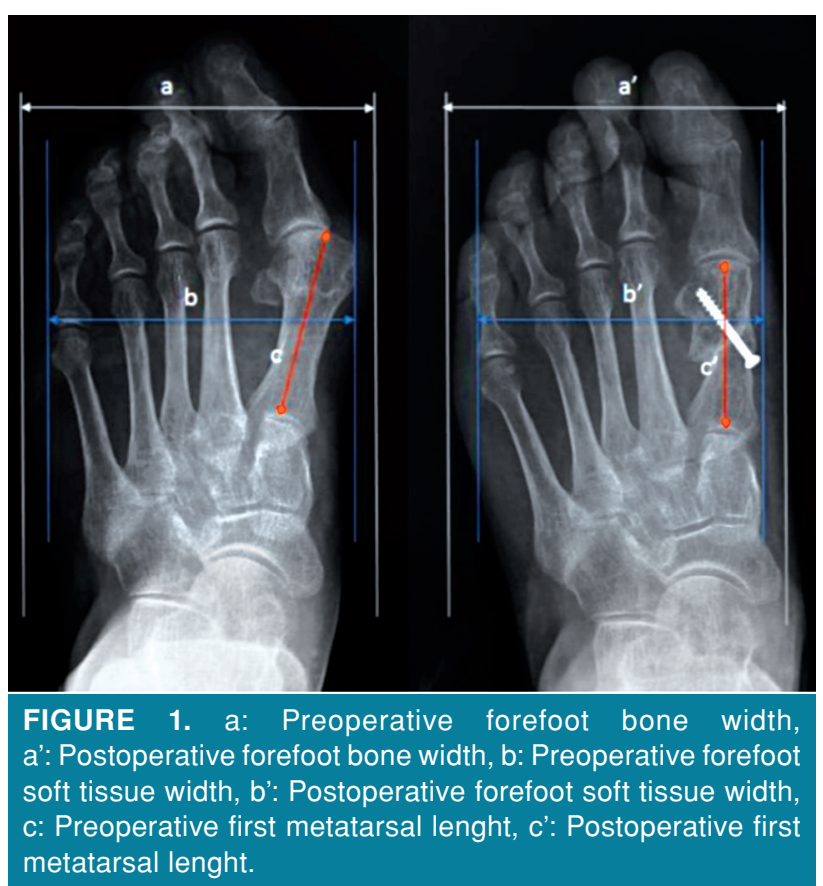



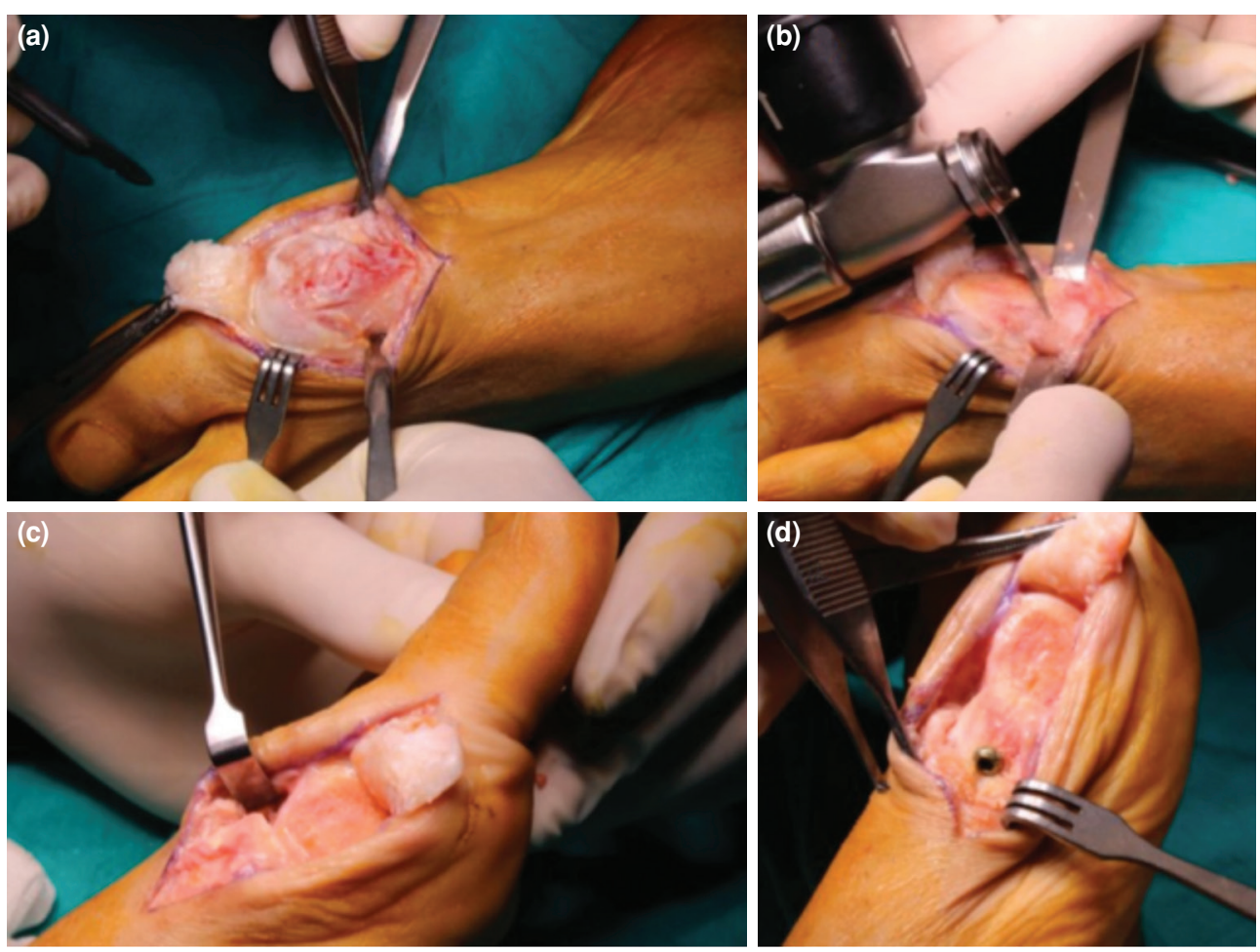

FIGURE 2. (a) U-shape opened joint capsule. (b) Distal medial-proximal lateral direction distal metatarsal osteotomy. (c) Bringing the thumb ideal position and sliding on the surface of osteotomy. (d) $4 \mathrm{~mm}$ cannulated screw used for fixation.

The distal fragment containing the first metatarsal head was shifted to the plantar side in the sagittal plane and the cascade was formed in the osteotomy area. In the sagittal plane, care was taken to align the first and second metatarsal heads in the same level. A $4 \mathrm{~mm}$ cannulated compression screw was used for fixation of distal fragment after the appropriate positioning (Figure 2d).

On first day postoperatively, patients were allowed to walk with an orthosis allowing transfer of load from heel. The sutures were removed at 21 days postoperatively. At six weeks postoperatively, full weight bearing was allowed if the union was seen on radiographs.

\section{Statistical analysis}

The statistical analysis of the data was performed by using the IBM SPSS version 22.0 for Windows software (IBM Corp., Armonk, NY, USA) . Relevance of variables to normal distribution was assessed with visual (histogram and probability graphs) and analytical methods. In the descriptive statistics section, categorical variables were presented as number, percentage, and continuous variables were presented as mean \pm standard deviation for normally distributed data and median (minimum-maximum) for data not normally distributed. The comparisons between the dependent groups were performed with the Wilcoxon test using the median and minimummaximum values, and the statistical significance level was accepted as $\mathrm{p}<0.05$.

\section{RESULTS}

The mean follow-up time was $33.1 \pm 9.8$ months. Five of 26 feet (22.7\%) were right, 13 were left $(22.7 \%)$, and four were bilateral (18.2\%).

In the radiological evaluation, the HVA, IMA, DMAA, and first metatarsal length decreased significantly $(p=0.001)$ (Table I). Forefoot bone and soft tissue width also decreased postoperatively $(\mathrm{p}=0.001)$ (Table I). According to Zettl method, ${ }^{[9]}$ eight of 26 feet were evaluated as stage 3, 13 as stage 2, four as stage 1 , and one as stage 0 . After the last follow-up, there was no stage 3 sesamoid position, whereas stage 2 was in 1 foot, stage 1 in 14 feet and stage 0 in 11 feet (Figure 3).

Total AOFAS/HMIS score was significantly higher than the preoperative period $(p=0.001)$. Furthermore, a significant difference was also 

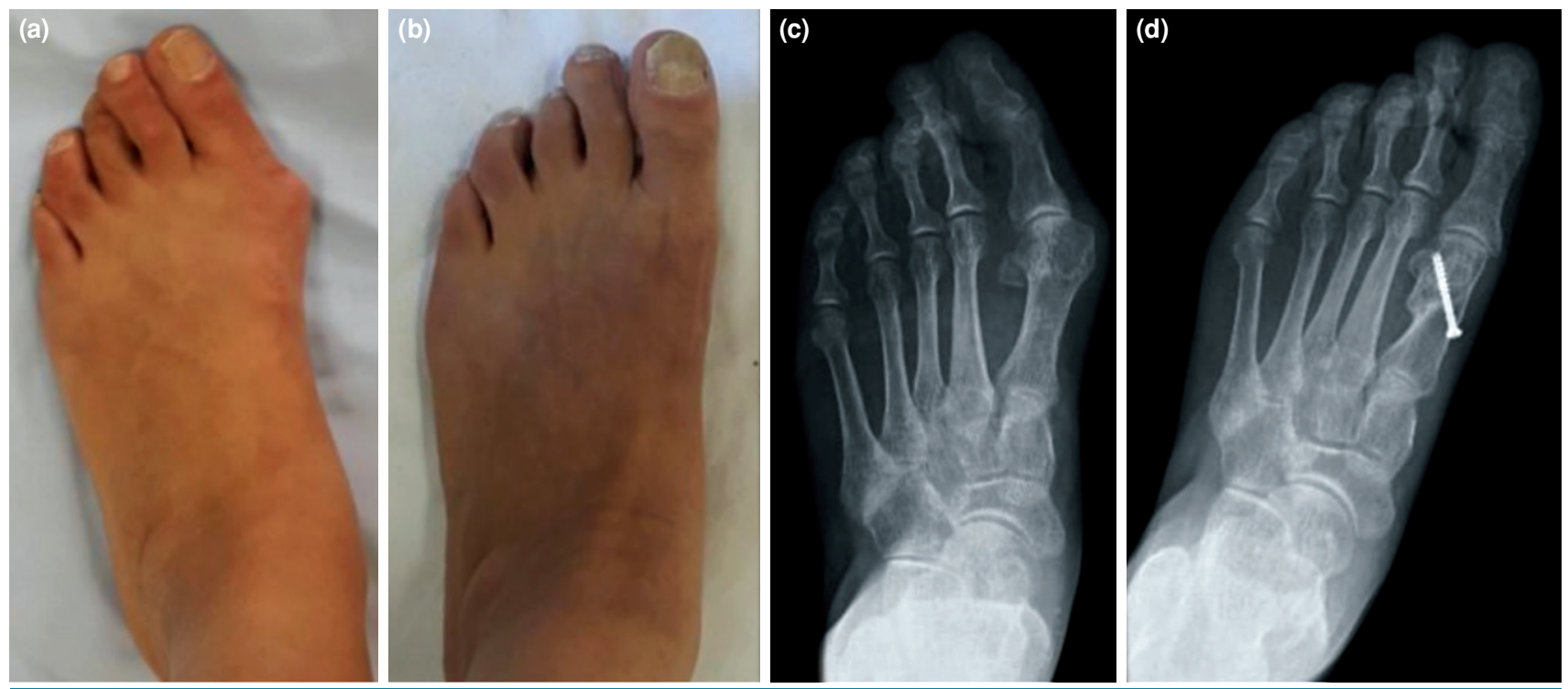

FIGURE 3. Fifty-one year old woman operated for hallux valgus deformity. (a) Preoperative AP weight-bearing view. (b) Postoperative AP weight-bearing view at last visit. (c) Preoperative AP weight-bearing X-ray. (d) Postoperative AP weightbearing $X$-ray at last visit.

AP: Anteroposterior.

obtained between pre- and postoperative pain, function, and alignment sections of the AOFAS/ HMIS. In the footwear section of the AOFAS/HMIS, the median preoperative score of 5 (range, 0-5) increased to 10 (range, 5-10) in the postoperative period $(\mathrm{p}=0.001)$ (Table II).

There was also a significant change in VAS pain and satisfaction scores pre- and postoperatively. The median preoperative VAS pain score was 8 (range, 2-10) while the median postoperative VAS pain score was 2 (range, 1-9). The median postoperative VAS pain scores of the patients showed a statistically significant decrease compared to the preoperative period $(\mathrm{p}=0.001)$. The median postoperative VAS satisfaction score was 8 (range, 2-10).
Postoperatively, superficial infection was seen in two patients and it healed with antibiotic treatment. In one patient, screw migration was observed in the third month follow-up and the screw was removed. Two patients had metatarsalgia for the second and third ray at the last follow-up.

\section{DISCUSSION}

The aim of surgical treatment for hallux valgus is to correct the deformity and decrease the symptoms to enable the patients to continue their sports activities, and social and professional life. Several methods were described for correcting the hallux valgus deformity in the literature and gratifying radiological results were obtained; however, complication rates after

TABLE I

Pre- and postoperative radiographic parameters

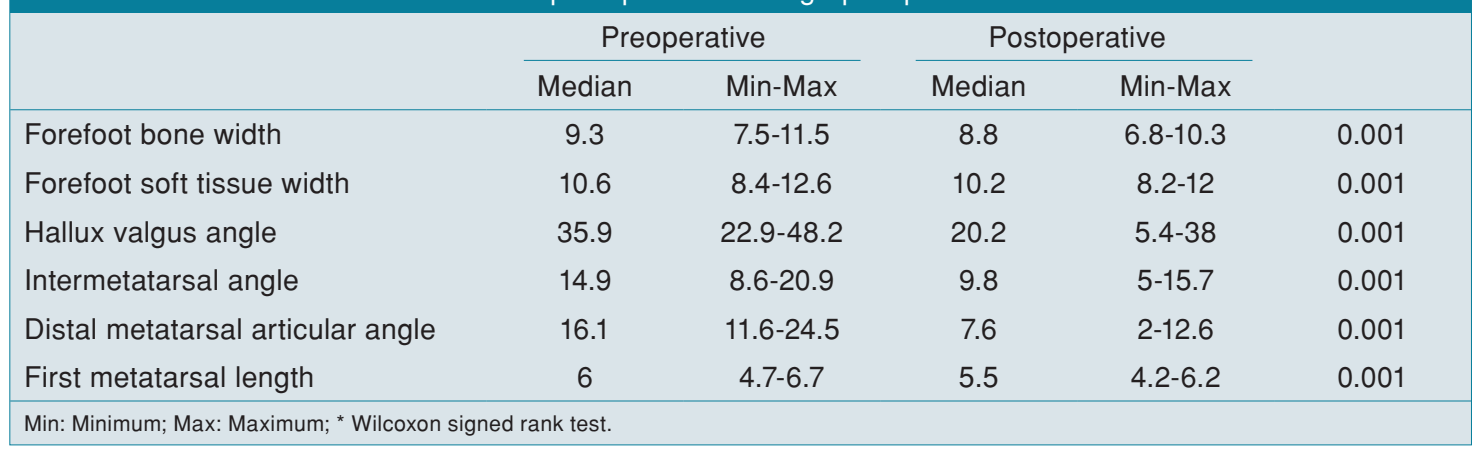




\begin{tabular}{|c|c|c|c|c|c|}
\hline & and post & $\begin{array}{l}\text { BLE II } \\
\text { tive clinice }\end{array}$ & ameters & & \\
\hline & Pre & ative & Pos & ative & \\
\hline & Median & Min-Max & Median & Min-Max & \\
\hline AOFAS total & 41 & $25-73$ & 87.5 & $33-100$ & 0.001 \\
\hline AOFAS pain & 0 & $0-30$ & 30 & $0-40$ & 0.001 \\
\hline AOFAS function & 30 & $25-40$ & 40 & $25-45$ & 0.001 \\
\hline AOFAS alignment & 8 & $0-8$ & 15 & $8-15$ & 0.001 \\
\hline AOFAS footwear requirements & 5 & $0-5$ & 10 & $5-10$ & 0.001 \\
\hline AOFAS activity limitations & 4 & $0-10$ & 10 & $0-10$ & 0.001 \\
\hline
\end{tabular}

surgery and patient's dissatisfaction could be higher than expected. ${ }^{[10]}$ Although the expectation of patients after surgical treatment is painless footwear, only $60 \%$ of this expectation can be met. ${ }^{[11]}$ The main finding of this study is that forefoot narrowing achieved after oblique osteotomy is significant for the patient's satisfaction and painless footwear.

Transfer metatarsalgia is a significant complication affecting patient satisfaction after hallux valgus surgery and it is more frequent than expected. ${ }^{[12]}$ In the literature, there are some studies stating that transfer metatarsalgia has increased as a result of certain methods which cause shortening of the first metatarsal length. ${ }^{[13,14]}$ However, other studies have shown that this complication may be reduced after fixing the distal fragment of the osteotomized first metatarsal in the plantar direction. ${ }^{[15-17]}$ Guler et al. ${ }^{[17]}$ applied distal oblique metatarsal osteotomy (modified Wilson osteotomy) and Chevron osteotomy to their series. The distal fragment was fixed in $1 \mathrm{~mm}$ plantarized position and the mean shortening of the first metatarsal was $0.68 \mathrm{~cm}$. They reported no significant difference between the two groups in terms of postoperative transfer metatarsalgia. Lambers Heerspink et al. ${ }^{[18]}$ applied a modified Chevron osteotomy and Mitchell osteotomy to their series. They reported the mean shortening as $0.44 \mathrm{~cm}$ in Chevron osteotomy group and $0.66 \mathrm{~cm}$ in Mitchell osteotomy group. They also found no significant difference between the two groups in terms of transverse metatarsalgia. Moreover, Scharer and DeVries $^{[19]}$ also compared Chevron osteotomy and distal oblique osteotomy methods in their series. Although they did not measure the first metatarsal shortening, increase in metatarsalgia was not found in distal oblique osteotomy group. They reported that distal oblique osteotomy is effective on both radiographic correction and patient satisfaction as well as Chevron osteotomy. In the present study, there were two patients complaining of transfer metatarsalgia. This finding was consistent with the literature. ${ }^{[17-19]}$ As explained in the surgical method, we believe that plantarization of the distal fragment in the sagittal plane can reduce the incidence of transfer metatarsalgia despite the shortening in the first metatarsal.

Unlike other studies in the literature, ${ }^{[17-19]}$ anterior forefoot width was also a radiological measurement method in the present study. As Perera et al. ${ }^{[3]}$ stated in their study about pathogenesis of hallux valgus deformity, repeated load transfer from the medial of the first metatarsal to the shoe will accelerate the formation and recurrence of hallux valgus deformity. In present study, significant decrease in forefoot bone and soft tissue widths was obtained. We therefore suggest that measuring the forefoot width is as vital as measuring the HVA, IMA, and DMAA.

Sesamoid reduction is also a significant subject to prevent transfer metatarsalgia and recurrences. As shown in the literature, sesamoid reduction increases the weight-bearing capacity in the first metatarsal. ${ }^{[16-18,20]}$ Okuda et al. ${ }^{[21]}$ pointed out the importance of sesamoid reduction in their study and reported that inadequate sesamoid reduction could cause recurrence. Likewise, Lee et al. ${ }^{[22]}$ reported a higher risk of recurrence in patients with incomplete sesamoid reduction after proximal Chevron osteotomy. We believe that the shortening of the first metatarsal with the soft tissue and plantar fascia loosening in distal oblique metatarsal osteotomy method helped sesamoid reduction and thus decreased recurrence and transfer metatarsalgia in the present study. 
In patients with hallux valgus deformity, the reason for the increased deformity during balanced standing is the pronation effect of weight-bearing loads and the tightening and shortening of the plantar aponeurosis. This causes patients to have resistance to dorsiflexion of the thumb during heel take off due to tension and shortness in the plantar fascia. ${ }^{[3]}$ Sanders et al. ${ }^{[23]}$ reported the effects of flexion moment acting on the MTP joint in their biomechanical study. According to this study, in patients with hallux valgus deformity, flexion moment acting on MTP joint increased the deformity during balanced standing while pushing the great toe on the ground. Fenton and McGlamry ${ }^{[24]}$ also indicated soft tissue balancing would reduce the force acting on the first metatarsal and hallux. We believe that the decrease in VAS pain score and increase in AOFAS/HMIS footwear section obtained in present study may result from soft tissue balancing effect of distal oblique metatarsal osteotomy.

The weaknesses of this study are its retrospective design and limited sample size. However, despite these limitations, the results of this study provided preliminary information for future prospective, randomized clinical trials with larger samples regarding distal oblique metatarsal osteotomy. In addition, to the best of our knowledge, this is the first study defining the forefoot width for hallux valgus surgery.

In conclusion, pain after hallux valgus surgery and the limitation in the choice of footwear are due to the inability to reduce the postoperative forefoot width, and achieve sesamoid reduction and plantar fascia relaxation. The most significant advantages of the current technique were the forefoot width shortening achieved compared to other methods and the prevention of recurrent painful bunion formation.

\section{Declaration of conflicting interests}

The authors declared no conflicts of interest with respect to the authorship and/or publication of this article.

\section{Funding}

The authors received no financial support for the research and/or authorship of this article.

\section{REFERENCES}

1. Baca E, Tuy E, Çelen KM. Can radiology reflect patient satisfaction after hallux valgus surgery? Eklem Hastalik Cerrahisi 2019;30:241-5.

2. Piqué-Vidal C, Solé MT, Antich J. Hallux valgus inheritance: pedigree research in 350 patients with bunion deformity. J Foot Ankle Surg 2007;46:149-54.
3. Perera AM, Mason L, Stephens MM. The pathogenesis of hallux valgus. J Bone Joint Surg [Am] 2011;93:1650-61.

4. Sim-Fook L, Hodgson AR. A comparison of foot forms among the non-shoe and shoe-wearing Chinese population. J Bone Joint Surg [Am] 1958;40:1058-62.

5. Kato T, Watanabe S. The etiology of hallux valgus in Japan. Clin Orthop Relat Res 1981;157:78-81.

6. Menz HB, Roddy E, Marshall M, Thomas MJ, Rathod T, Peat GM, et al. Epidemiology of shoe wearing patterns over time in older women: associations with foot pain and hallux valgus. J Gerontol A Biol Sci Med Sci 2016;71:1682-7.

7. Saro C, Jensen I, Lindgren U, Felländer-Tsai L. Qualityof-life outcome after hallux valgus surgery. Qual Life Res 2007;16:731-8.

8. Atik OŞ. Which articles do we prefer to publish? Eklem Hastalik Cerrahisi 2018;29:1.

9. Zettl R, Trnka HJ, Easley M, Salzer M, Ritschl P. Moderate to severe hallux valgus deformity: correction with proximal crescentic osteotomy and distal soft-tissue release. Arch Orthop Trauma Surg 2000;120:397-402.

10. Barg A, Harmer JR, Presson AP, Zhang C, Lackey M, Saltzman CL. Unfavorable Outcomes Following Surgical Treatment of Hallux Valgus Deformity: A Systematic Literature Review. J Bone Joint Surg [Am] 2018;100:1563-73.

11. Robinson AH, Limbers JP. Modern concepts in the treatment of hallux valgus. J Bone Joint Surg [Br] 2005;87:1038-45.

12. Maceira E, Monteagudo M. Transfer metatarsalgia post hallux valgus surgery. Foot Ankle Clin 2014;19:285-307.

13. Givissis P, Karataglis D, Christodoulou A, Terzidis I, Pournaras J. Wilson osteotomy stabilised by means of internal fixation for the treatment of hallux valgus. Acta Orthop Belg 2004;70:57-63.

14. Tóth K, Huszanyik I, Kellermann P, Boda K, Róde L. The effect of first ray shortening in the development of metatarsalgia in the second through fourth rays after metatarsal osteotomy. Foot Ankle Int 2007;28:61-3.

15. Barouk P. Recurrent metatarsalgia. Foot Ankle Clin 2014;19:407-24.

16. Kraus T, Singer G, Svehlík M, Kaltenbach J, Eberl R, Linhart W. Long-term outcome of chevron-osteotomy in juvenile hallux valgus. Acta Orthop Belg 2013;79:552-8.

17. Guler O, Yilmaz B, Mutlu S, Cerci MH, Heybeli N. Distal oblique metatarsal osteotomy for hallux valgus deformity: a clinical analysis. J Foot Ankle Surg 2017;56:497-504.

18. Lambers Heerspink FO, Verburg H, Reininga IH, van Raaij TM. Chevron versus Mitchell osteotomy in hallux valgus surgery: a comparative study. J Foot Ankle Surg 2015;54:361-4.

19. Scharer BM, DeVries JG. Comparison of chevron and distal oblique osteotomy for bunion correction. J Foot Ankle Surg 2016;55:738-42.

20. Pouliart N, Haentjens P, Opdecam P. Clinical and radiographic evaluation of Wilson osteotomy for hallux valgus. Foot Ankle Int 1996;17:388-94.

21. Okuda R, Kinoshita M, Yasuda T, Jotoku T, Kitano N, Shima $\mathrm{H}$. Postoperative incomplete reduction of the sesamoids as a risk factor for recurrence of hallux valgus. J Bone Joint Surg [Am] 2009;91:1637-45.

22. Lee KB, Kim MS, Park KS, Lee GW. Importance of postoperative sesamoid reduction on the outcomes of proximal chevron osteotomy for moderate to severe hallux valgus deformity. Foot Ankle Surg 2019;25:434-40. 
23. Sanders AP, Snijders CJ, van Linge B. Medial deviation of the first metatarsal head as a result of flexion forces in hallux valgus. Foot Ankle 1992;13:515-22.
24. Fenton CF 3rd, McGlamry ED. Reverse buckling to reduce metatarsus primus varus: a preliminary investigation. J Am Podiatry Assoc 1982;72:342-6. 